\title{
Effect of dibutyryl cyclic adenosine monophosphate on granulosa cell proliferation, oocyte growth and meiotic maturation in isolated mouse primary ovarian follicles cultured in collagen gels
}

\author{
J. Carroll, D. G. Whittingham and M. J. Wood \\ Medical Research Council Experimental Embryology \& Teratology Unit, St George's Hospital \\ Medical School, Cranmer Terrace, London SW17 ORE, UK
}

\begin{abstract}
Summary. Isolated primary follicles from 10-day-old mice were cultured in a collagen gel matrix for 6 days in Minimum Essential Medium + foetal calf serum, followed by culture in unsupplemented medium (control) or in medium containing hypoxanthine ( $2 \mathrm{~mm}$ ) or dibutyryl cyclic adenosine monophosphate (dbcAMP, $0.25 \mathrm{~mm}$ ) for a further 3 or 6 days. Less than $10 \%$ of oocytes resumed meiosis during the culture period in all groups. At recovery, the diameter of oocytes at the germinal vesicle stage was recorded and their ability to resume meiosis was determined. Hypoxanthine had little effect on oocyte growth and meiotic competence, but culture in dbcAMP resulted in oocytes that were larger $(60.2 \pm 0.6 \mu \mathrm{m})$ than those of controls $(55.8 \pm 0.5 \mu \mathrm{m})$ and more competent to resume meiosis than were controls $(42.9 \%$ and $10.8 \%$, respectively). The addition of dbcAMP to the culture medium induced a 4-5-fold increase in the number of granulosa cells/oocyte compared with controls $(3757 \pm 423$ and $838 \pm 93$, respectively). These results indicate that increased oocyte growth and meiotic competence is primarily mediated via dbcAMP effects on the granulosa cells.
\end{abstract}

Keyrords: primary follicle; oocyte; meiotic maturation; granulosa cell; mouse

\section{Introduction}

At birth, the mouse ovary is populated by non-growing follicles, each consisting of an oocyte arrested in the prophase stage of the first meiotic division surrounded by a layer of pregranulosa cells. The first wave of follicular growth occurs in the first week of life and is initiated by an, as yet, unknown mechanism. During the next 2-3 weeks, the oocyte grows from a diameter of $\sim 20$ to $70 \mu \mathrm{m}$ and there is a concurrent increase in the number of granulosa cells surrounding the oocyte. Meiosis resumes in response to a gonadotrophin signal just before ovulation or if the oocyte is removed from the inhibitory follicular environment (Pincus \& Enzman, 1935). Several molecules have been implicated as potential regulators of intrafollicular meiotic inhibition, based on their ability to prevent spontaneous maturation in vitro; these include hypoxanthine and cyclic adenosine $3^{\prime}, 5^{\prime}$-monophosphate (cAMP). Recent work has focused on the mechanism of meiotic regulation by these molecules, but little attention has been given to the conditions necessary for oocyte growth and the acquisition of meiotic competence.

Oocyte growth is dependent upon the metabolic coupling of the oocyte and the granulosa cells (Eppig, 1979; Heller et al., 1981; Brower \& Schultz, 1982; Herlands \& Schultz, 1984) and the maintenance of communication between granulosa cells and oocytes is essential for oocyte growth in vitro (Buccione et al., 1987). Collagen gels provide a 3-dimensional matrix which allows the development of unilaminar to multilaminar follicles in vitro (Torrance et al., 1989). Mature, fully 
viable oocytes can be obtained from fresh and frozen-thawed primary follicles grown and matured in collagen gels underneath the kidney capsule of recipient mice (Carroll et al, 1990). Similar numbers of oocytes from fresh and frozen-thawed primary follicles grow and acquire meiotic competence during a 12-day culture period in vitro (J. Carroll, unpublished). In other in-vitro systems used for development of primary follicles, the presence of hypoxanthine increased the proportion of oocytes that were competent to resume meiosis at the end of the culture period (Eppig \& Downs, 1987). Further, live young were obtained after oocytes grown in a similar culture system were matured and fertilized in vitro (Eppig \& Schroeder, 1989), but the important factors in the regulation of oocyte growth in vitro remain unknown.

In this study, we compared the effects of hypoxanthine and dibutyryl cyclic adenosine monophosphate (dbcAMP) on oocyte growth and granulosa cell proliferation during the culture of isolated primary follicles in a collagen gel matrix.

\section{Materials and Methods}

Follicle isolation. Follicle isolation and culture in collagen gels was carried out using a modified method of Torrance et al. (1989). Ovaries were removed from 10-day-old B6CB(C57BL/6J Lac $\times$ CBACa Lac) $F_{1}$ hybrid mice, bisected and incubated for $30 \mathrm{~min}$ at $37^{\circ} \mathrm{C}$ in medium M2 (Quinn et al., 1982) containing collagenase $(1.5 \mathrm{mg} / \mathrm{ml}$ : Sigma type 1) and DNAase $1(40 \mathrm{u} / \mathrm{ml}$ : Sigma). The ovarian fragments were collected in $1 \mathrm{ml}$ of this medium and transferred to a watch glass containing M2 supplemented with 5\% foetal calf serum (M2 + FCS; FCS, Flow Laboratories; Irvine, Scotland). Follicles were liberated by repeated pipetting of the fragments and, during the procedure, isolated follicles were removed to a watch glass containing fresh M2 + FCS. A suspension of isolated primary follicles free from other ovarian cells and debris was obtained by washing 4 times in M $2+$ FCS ( $2 \mathrm{ml} / \mathrm{wash}$ ). Using a mouthoperated, fine-bore pipette, individual follicles were collected and transferred to a dish of M2 + FCS. The follicles with an intact oocyte completely surrounded by granulosa cells were removed and pooled in M2 + FCS for culture in collagen gels.

Follicle culture. Morphologically normal primary follicles were suspended in separate collagen gels using a method of Torrance et al. (1989). Groups of 50 follicles were transferred in M2 + FCS to the wells of a Terasaki plate (Flow Laboratories). Excess medium was removed using a fine-bore pipette and the follicles were suspended in $10 \mu \mathrm{l}$ of collagen gel solution. The Terasaki plate was incubated at $37^{\circ} \mathrm{C}$ for $3-5 \mathrm{~min}$ to set the gel solution. This gel was then transferred to $20 \mu \mathrm{l}$ of gel solution, which was set as described above. The double gels were transferred to the wells (2/well) of a 24-well culture plate (Nunclon) containing $2 \mathrm{ml}$ of Minimum Essential Medium (MEM: Flow Laboratories) supplemented with $10 \%$ FCS, $2 \mathrm{~mm}$ glutamine, $0.33 \mathrm{~mm}$ pyruvate and antibiotics (MEM + FCS). Culture was at $37^{\circ} \mathrm{C}$ in a humidified atmosphere of $5 \% \mathrm{CO}_{2}$ in air. The medium was changed every 3 days.

Oocyte recovery and assessment of meiotic competence. Follicles were recovered at the end of the culture period by incubating the gel for $30-40 \mathrm{~min}$ at $37^{\circ} \mathrm{C}$ in $\mathrm{M} 2+\mathrm{FCS}$ containing collagenase $(1.5 \mathrm{mg} / \mathrm{ml})$. After release from the gels, follicles were washed twice in M2 + FCS and the granulosa cells were removed by repeated pipetting. The oocytes were counted and their stage of meiosis was recorded, i.e. intact germinal vesicle (GV), germinal vesicle breakdown (GVBD) or first polar body extruded $(\mathrm{Pbl})$. Oocytes not exhibiting an intact $\mathrm{GV}$ were then discarded. The diameter of the GV-stage oocytes was determined using a calibrated ocular micrometer fitted to a Leitz inverted microscope. To assess their meiotic competence, GV-stage oocytes were cultured overnight (18 h) in drops of medium M16 (Whittingham, 1971) overlayed with paraffin oil (BDH Chemicals; Poole, UK) at $37^{\circ} \mathrm{C}$ in an atmosphere of $5 \%$ $\mathrm{CO}_{2}$ in air. At the end of this culture period, the stage of meiosis of the oocytes was recorded.

In-vitro fertilization and embryo transfer. The procedures used have been described in detail by Glenister et al. (1987).

Histology. Gels were placed in Bouin's fixative, embedded in paraffin wax and serially sectioned at $7 \mu \mathrm{m}$. Sections were stained with an Azan stain.

Experiment 1. Collagen gels containing 50 follicles were cultured in MEM $+10 \%$ FCS for 6 days and then in unsupplemented medium (controls) or in medium supplemented with $2 \mathrm{~mm}$ hypoxanthine (Sigma Chemical Co., Poole, England), or $0.25 \mathrm{~mm}$ dbcAMP (Sigma Chemical Co.) for a further 3 or 6 days. Oocytes were recovered from the collagen gels and the stage of meiosis and the diameter of each GV-stage occyte were recorded. The meiotic competence of the GV-stage oocytes was determined as described above. During the culture of isolated primary follicles, there was a marked proliferation of granulosa cells when cultured in the presence of dbcAMP (Fig. Ic); a second experiment was carried out to determine the extent of this effect.

Experiment 2. Follicles were cultured in collagen gels for 6 days in MEM $+10 \%$ FCS and for a further 6 days in the same medium containing $0.25 \mathrm{~mm}$ dbcAMP. At the end of the culture period, three gels were pooled in a watch 
glass containing M2 + FCS supplemented with $1.5 \mathrm{mg}$ collagenase $/ \mathrm{ml}$ and the follicles were recovered. After denuding, the number of oocytes recovered from each group of three gels was recorded. Granulosa cells were collected from the watch glass using a Gilson pipette and transferred to a centrifuge tube $(10 \mathrm{ml})$. The dish was rinsed 3 times using fresh M2 + FCS. The sample was centrifuged at $300 \mathrm{~g}$ for $10 \mathrm{~min}$, the supernatant was removed and the cells were resuspended in $7 \mathrm{ml}$ phosphate-buffered saline. After pelleting, the cells were resuspended in $50 \mu 10.25 \%$ trypsin (Gibco; Uxbridge, England), incubated at $37^{\circ} \mathrm{C}$ for $10 \mathrm{~min}$ and pipetted to break up the clumps of cells. Then $50 \mu 1$ M2 + FCS were used to neutralize the trypsin and cells were counted using a haemocytometer and phase-contrast microscope. Cells were counted 4-8 times in 3 separate experiments. To determine the number of granulosa cells/ oocyte at the start of culture, primary follicles were collected from 10-day-old mice and pooled into groups of 150 . Follicles were processed in the same way as described above.

Statistical analysis. The numbers of oocytes recovered and meiotic competence were analysed by ANOVA after arc sin transformation. Mean oocyte diameter and the numbers of granulosa cells recovered were analysed using the Student's $t$ test.

\section{Results}

\section{Oocyte recovery}

Overall, more oocytes were recovered on Day 9 than on Day $12(P<0.01$; Table 1$)$. The presence of hypoxanthine or dbcAMP in the culture medium did not significantly affect the total number of oocytes recovered. Most of the oocytes recovered were in the GV stage. On Day 12 of culture, more oocytes in the GV stage were recovered in the dbcAMP medium than in control or hypoxanthine-containing medium $(P<0 \cdot 05)$.

\section{Meiotic competence of GV-stage oocytes}

After culture of GV-stage oocytes for $18 \mathrm{~h}$, the proportion of oocytes resuming meiosis (GVBD $+\mathrm{Pb} 1)$ was highest in the dbcAMP group on Days $9(P<0.01)$ and $12(P<0.01)$ (Table 2 ). This was reflected by a higher proportion of oocytes from the dbcAMP group which completed meiotic maturation and extruded the first polar body (Table 2; Fig. 2). The presence of hypoxanthine in the culture medium resulted in an increase in the proportion of oocytes which resumed meiosis compared with controls and this increase was reflected in more oocytes undergoing GVBD rather than reaching the $\mathrm{Pbl}$ stage (Table 2).

From Day 9 to Day 12 the proportion of oocytes resuming meiosis increased in the dbcAMP group $(P<0.01)$ but not in the control or hypoxanthine groups (Table 2 ).

\section{Oocyte growth during Days 9-12 in culture}

The mean oocyte diameter at the start of culture was $48 \pm 0 \cdot 2 \mu \mathrm{m}$; during the next 9 days it increased (Table 3). The presence of hypoxanthine or dbcAMP had no significant effect on oocyte diameter at this stage $(P>0 \cdot 2)$. By Day 12, the oocytes from primary follicles cultured in medium containing dbcAMP had continued to grow, reaching a mean diameter of $60 \cdot 2 \pm 0.6 \mu \mathrm{m}$. Although this was not significantly different from the Day 9 value $(P>0.05)$, it was significantly higher $(P<0.001$; Table 3$)$ than the diameter of oocytes grown in control or hypoxanthine-containing medium. The control and hypoxanthine groups did not increase in diameter significantly between Days 9 and 12 (Table 3).

There was no marked difference in the distribution of oocyte diameters after 9 days in culture, but the highest proportion of oocytes cultured in control or hypoxanthine-containing medium were $50-55 \mu \mathrm{m}$ in diameter, compared with $55-60 \mu \mathrm{m}$ in the dbcAMP group (Fig. 3a). This trend had increased markedly by Day 12 of culture, such that more oocytes from primary follicles cultured in dbcAMP attained a diameter of $>60 \mu \mathrm{m}(62 \%)$ compared with the control $(24 \%)$ and hypoxanthine $(24 \%)$ groups (Fig. 3b). 


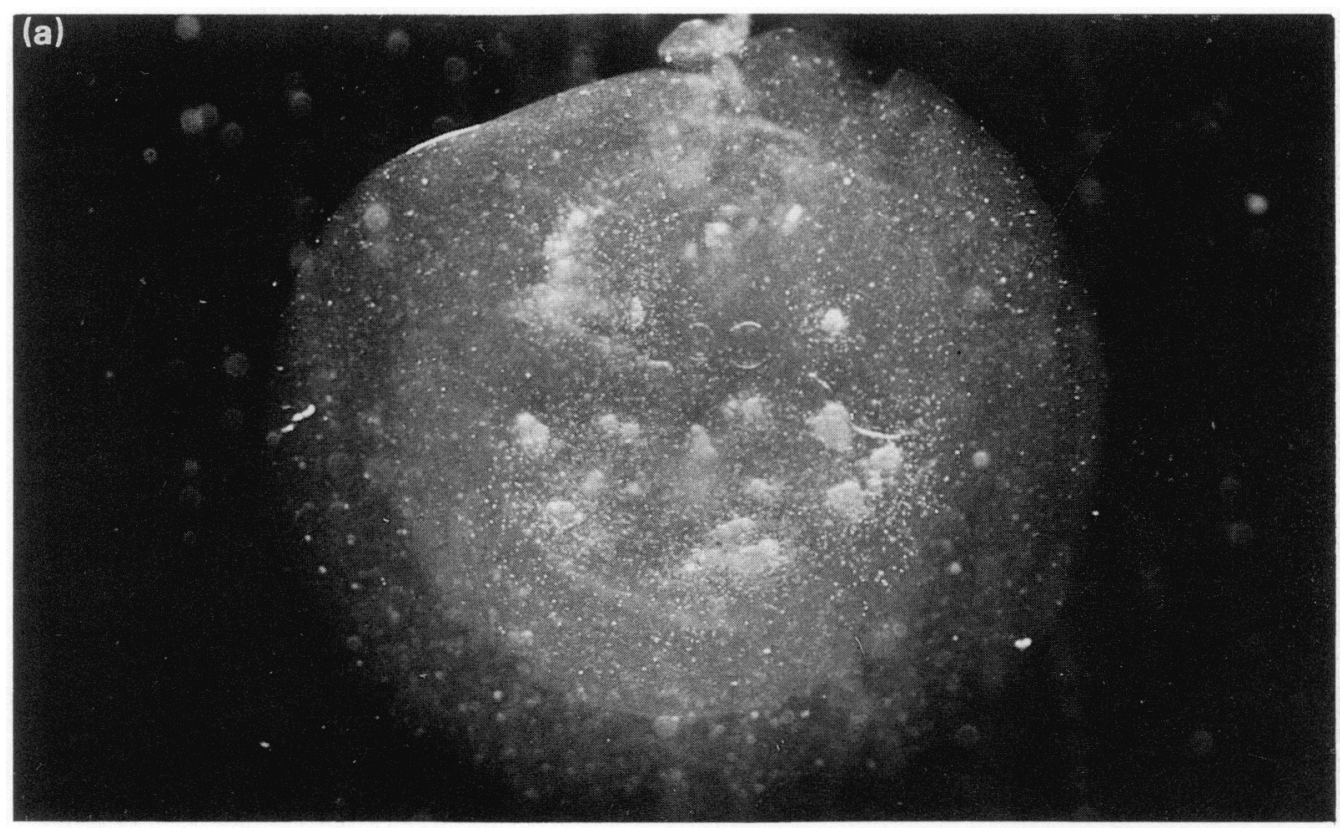

Fig. 1.(a)

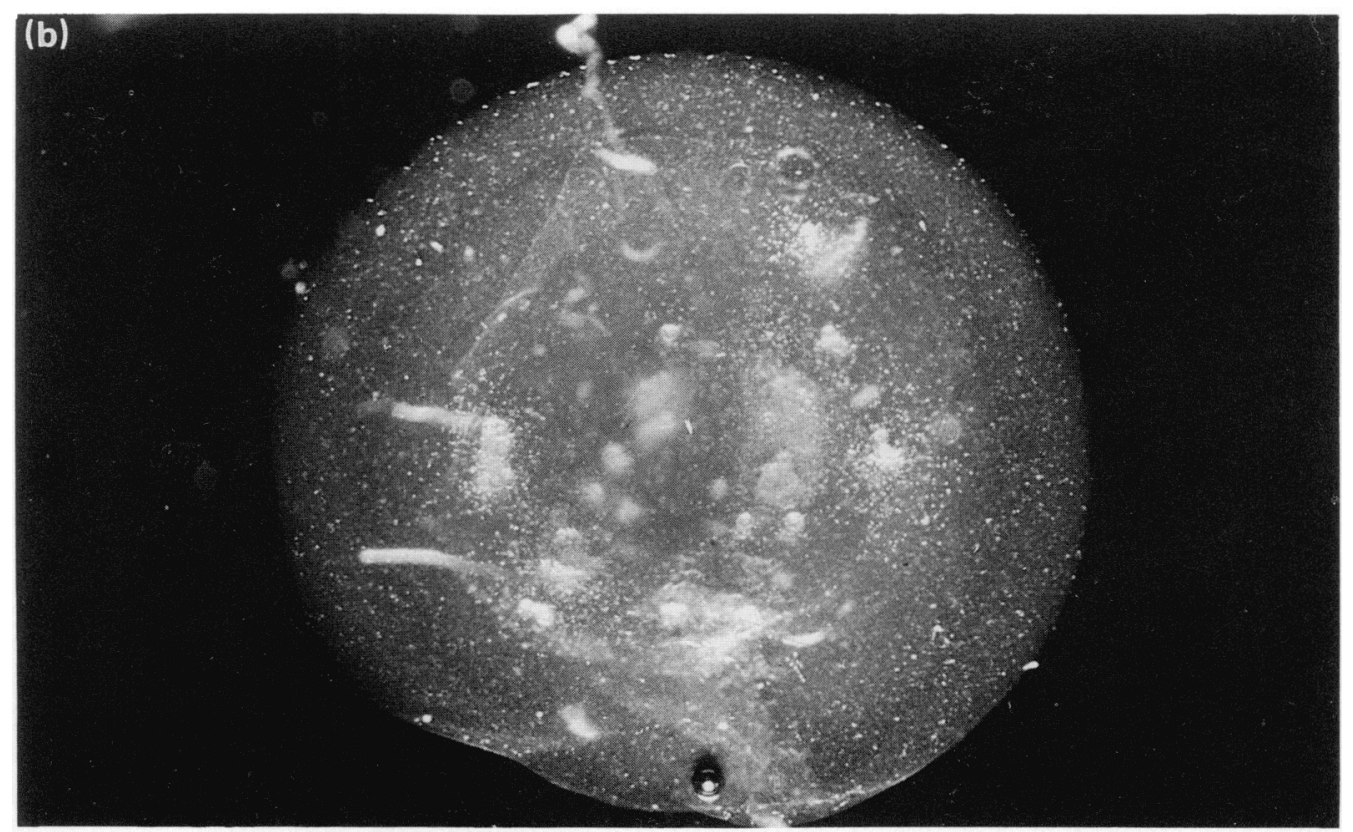

Fig. 1 (b)

Downloaded from Bioscientifica.com at ๑4/26/2023 09:21:43AM 


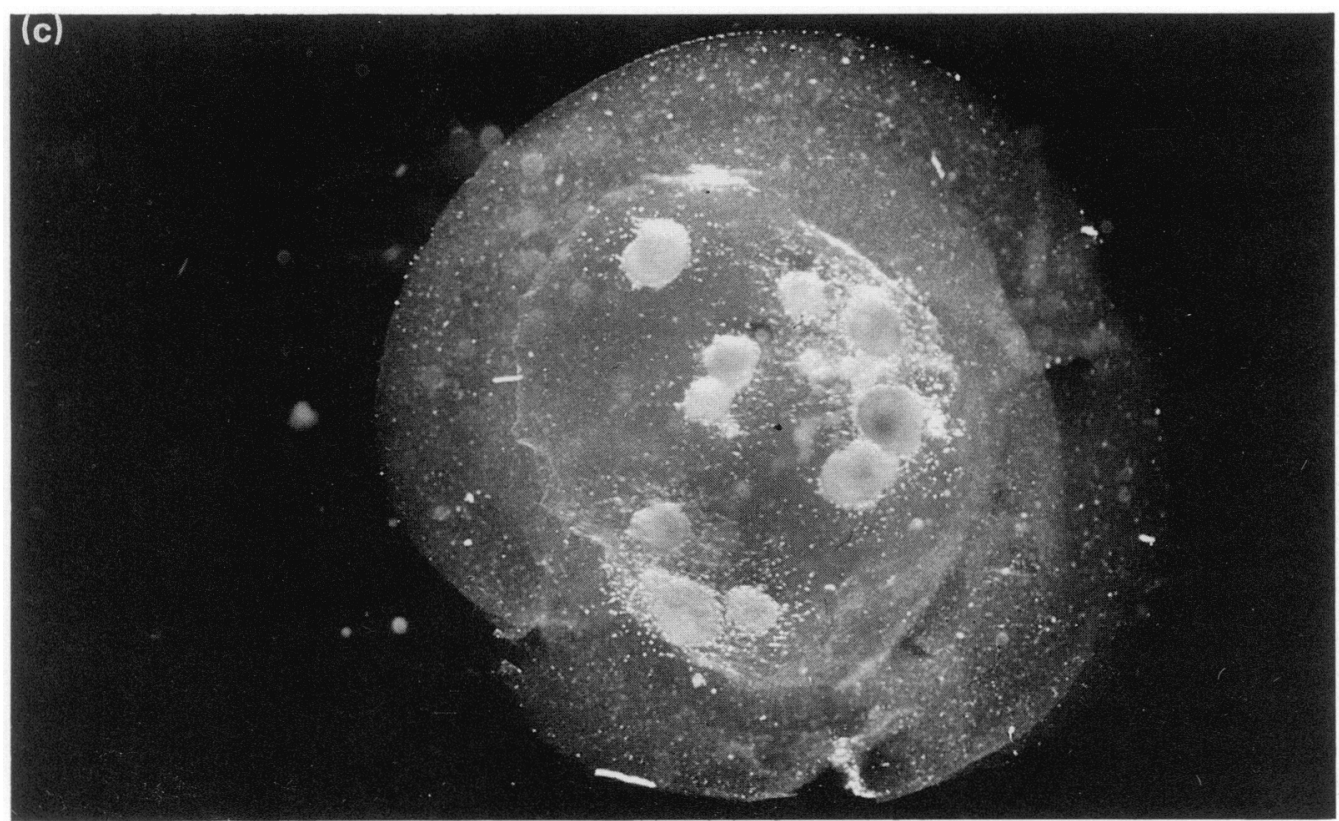

Fig. 1. (c)

Fig. 1. Collagen gels containing isolated primary mouse follicles cultured for 12 days in (a) control medium or in medium containing (b) hypoxanthine or (c) dibutyryl cyclic adenosine monophosphate (dbcAMP) added on Day 6 of culture. Note the marked increase in the size of the follicular units after culture in $\operatorname{dbcAMP}(c) . \times 60$.

Table 1. Meiotic status of mouse oocytes recovered from isolated primary follicles treated with hypoxanthine or dibutyryl cyclic adenosine monophosphate (dbcAMP) from Day 6 to Day 9 or 12 of culture*

\begin{tabular}{|c|c|c|c|c|c|c|c|c|}
\hline \multirow[b]{2}{*}{$\begin{array}{l}\text { Time in } \\
\text { culture } \\
\text { (dilys) }\end{array}$} & \multirow[b]{2}{*}{$\begin{array}{l}\text { Treatment } \\
\text { from Day } 6 \\
\text { of culture }\end{array}$} & \multirow[b]{2}{*}{$\begin{array}{l}\text { No. of } \\
\text { follicles } \\
\text { cultured }\end{array}$} & \multirow[b]{2}{*}{$\begin{array}{l}\text { No. of } \\
\text { oocytes } \\
\text { recovered } \\
(\%)\end{array}$} & \multicolumn{4}{|c|}{$\%$ Stage of meiosis at recovery } & \multirow[b]{2}{*}{$\begin{array}{c}\text { Total } \% \\
\text { resuming } \\
\text { meiosis }\end{array}$} \\
\hline & & & & $\begin{array}{c}\text { Germinal } \\
\text { vesicle }\end{array}$ & $\begin{array}{l}\text { Germinal } \\
\text { vesicle } \\
\text { breakdown }\end{array}$ & $\begin{array}{l}\text { First polar } \\
\text { body } \\
\text { extruded }\end{array}$ & Degenerate & \\
\hline \multirow[t]{4}{*}{9} & None & 300 & $208(69 \cdot 3)$ & $96 \cdot 6$ & $0 \cdot 5$ & $2 \cdot 0$ & 1.0 & $2 \cdot 5$ \\
\hline & Hypoxanthine & 300 & $211(70 \cdot 3)$ & 95.7 & 1.5 & $1 \cdot 4$ & 1.5 & $2 \cdot 9$ \\
\hline & dbcAMP & 300 & $196(65 \cdot 3)$ & 99 & 1 & 0 & 0 & $0 \cdot 5$ \\
\hline & Total & 900 & $615(68 \cdot 3)^{\mathrm{a}}$ & & & & & \\
\hline \multirow[t]{4}{*}{12} & None & 300 & $172(57 \cdot 3)$ & $89 \cdot 5$ & $4 \cdot 7$ & $2 \cdot 3$ & 3.5 & $7 \cdot 0$ \\
\hline & Hypoxanthine & 300 & $170(56 \cdot 6)$ & $90 \cdot 6$ & $4 \cdot 1$ & $3 \cdot 0$ & $2 \cdot 3$ & $7 \cdot 0$ \\
\hline & dbcAMP & 300 & $190(63 \cdot 3)$ & $100^{c}$ & 0 & 0 & 0 & 0 \\
\hline & Total & 900 & $532(59 \cdot 1)^{\mathrm{b}}$ & & & & & \\
\hline
\end{tabular}

* Combined results of 3 replicate experiments.

Significantly different from values in column of same day $(P<0.01)$.

Values in the same column with different superscripts are significantly different. $(P<0.01)$. 
Table 2. Ability of mouse oocytes at the germinal vesicle stage and free of granulosa cells to resume meiosis after recovery from isolated primary follicles treated with hypoxanthine or dibutyryl cyclic adenosine monophosphate (dbcAMP) from Day 6 to Day 9 or 12 of culture*

\begin{tabular}{|c|c|c|c|c|c|c|c|}
\hline \multirow[b]{2}{*}{$\begin{array}{l}\text { Time in } \\
\text { culture } \\
\text { (days) }\end{array}$} & \multirow[b]{2}{*}{$\begin{array}{l}\text { Treatment } \\
\text { from Day } 6 \\
\text { of culture }\end{array}$} & \multirow{2}{*}{$\begin{array}{c}\text { No. of } \\
\text { oocytes } \\
\text { at the germinal } \\
\text { vesicle stage } \\
\text { cultured }\end{array}$} & \multicolumn{4}{|c|}{$\%$ Stage of meiosis after $18 \mathrm{~h}$ culture } & \multirow[b]{2}{*}{$\begin{array}{c}\text { Total \% } \\
\text { resuming } \\
\text { meiosis }\end{array}$} \\
\hline & & & $\begin{array}{l}\text { Germinal } \\
\text { vesicle }\end{array}$ & $\begin{array}{l}\text { Germinal } \\
\text { vesicle } \\
\text { breakdown }\end{array}$ & $\begin{array}{l}\text { First polar } \\
\text { body } \\
\text { extruded }\end{array}$ & Degenerate & \\
\hline \multirow[t]{4}{*}{9} & None & 201 & 92 & $5 \cdot 4$ & $2 \cdot 6$ & 0 & $8 \cdot 0^{\mathrm{a}}$ \\
\hline & Hypoxanthine & 195 & $84 \cdot 1$ & $12 \cdot 3$ & 3.6 & 0 & $15 \cdot 9^{\mathrm{b}}$ \\
\hline & dbcAMP & 194 & $77 \cdot 4$ & $10 \cdot 8$ & $11 \cdot 8$ & 0 & $29 \cdot 3^{\mathrm{c}}$ \\
\hline & Total & 583 & $84 \cdot 5$ & $9 \cdot 5$ & $6 \cdot 0$ & 0 & $15 \cdot 5$ \\
\hline \multirow[t]{4}{*}{12} & None & 148 & $87 \cdot 2$ & $6 \cdot 8$ & $4 \cdot 0$ & 2 & $10 \cdot 8^{\mathrm{ab}}$ \\
\hline & Hypoxanthine & 167 & $74 \cdot 3$ & $14 \cdot 4$ & $4 \cdot 2$ & $7 \cdot 1$ & $18 \cdot 6^{\mathrm{b}}$ \\
\hline & dbcAMP & 189 & $56 \cdot 1$ & $21 \cdot 2$ & $21 \cdot 7$ & $1 \cdot 0$ & $42 \cdot 9^{\mathrm{d}}$ \\
\hline & Total & 545 & $72 \cdot 5$ & $14 \cdot 1$ & $10 \cdot 0$ & $3 \cdot 4$ & $24 \cdot 1$ \\
\hline
\end{tabular}

${ }^{*}$ Combined results of 3 replicate experiments.

Values in the same column with different superscripts are significantly different $(P<0.05)$.

Table 3. Diameter of mouse oocytes recovered at the germinal vesicle stage from isolated primary follicles treated with hypoxanthine or dibutyryl cyclic adenosine monophosphate (dbcAMP) from

Day 6 to Day 9 or 12 of culture

\begin{tabular}{|c|c|c|}
\hline \multirow{3}{*}{$\begin{array}{l}\text { Treatment } \\
\text { from } \\
\text { Day } 6 \\
\text { of culture }\end{array}$} & \multicolumn{2}{|c|}{ Mean oocyte diameter $(\mu \mathrm{m})^{*}$} \\
\hline & \multicolumn{2}{|c|}{ After a total of } \\
\hline & 9 days' culture & 12 days' culture \\
\hline None & $56 \cdot 0 \pm 1 \cdot 0$ & $55 \cdot 8 \pm 0 \cdot 5$ \\
\hline $\begin{array}{l}\text { Hypoxanthine } \\
(2 \mathrm{~mm})\end{array}$ & $55 \cdot 7 \pm 1 \cdot 0$ & $55 \cdot 3 \pm 1 \cdot 4$ \\
\hline $\begin{array}{l}\text { dbcAMP } \\
(0.25 \mathrm{mM})\end{array}$ & $57 \cdot 3 \pm 1 \cdot 2$ & $60 \cdot 2 \pm 0 \cdot 6^{a}$ \\
\hline
\end{tabular}

\section{Effect of dbcAMP on number of granulosa cells}

The mean number of granulosa cells surrounding each oocyte on Day 0 was estimated to be $164 \pm 38$. During 12 days' culture in control conditions, the number of granulosa cells/oocyte increased significantly $(P<0 \cdot 01$; Table 4$)$. The addition of dbcAMP to the culture medium significantly increased the number of granulosa cells/oocyte recovered, 4-5 times more than in control cultures $(P<0.001 ;$ Table 4$)$.

\section{In-vitro fertilization}

Of 63 oocytes inseminated, $18(35 \%)$ cleaved to the 2-cell stage. Preliminary observations on oocytes which failed to cleave showed that many had been penetrated by spermatozoa and in some there were $>2$ pronuclei. Fourteen 2-cell embryos were transferred to the oviducts of pseudopregnant recipient females, but no live young were born. 

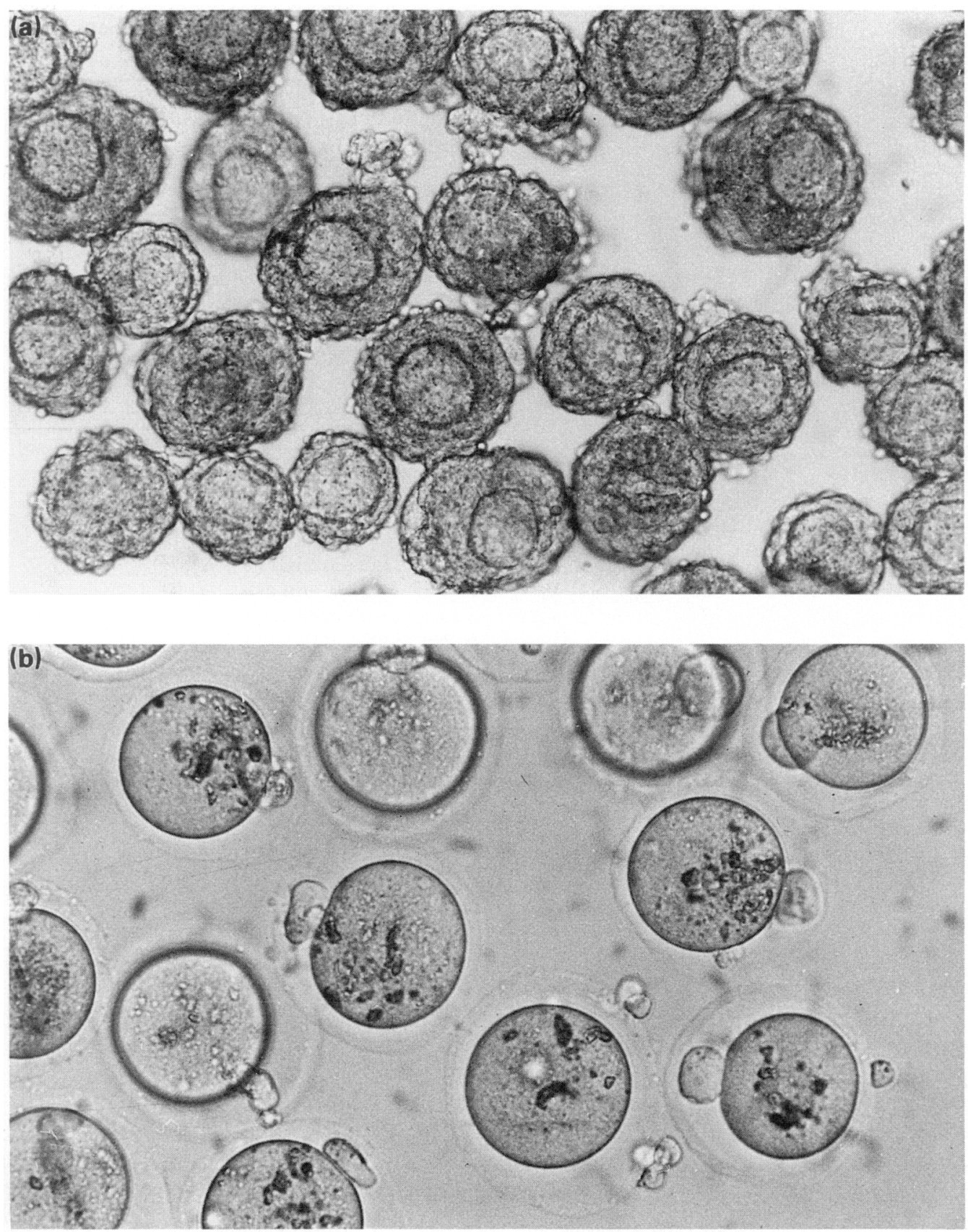

Fig. 2. (a) Primary follicles isolated from the ovaries of 10-day-old mice. Note the oocyte completely surrounded by 1 or 2 layers of granulosa cells $\times 250$. (b) Mature oocytes in metaphase II obtained after the maturation of oocytes recovered at the germinal vesicle stage from isolated primary follicles and cultured in collagen gels for 12 days; dibutyryl cyclic adenosine monophosphate was added to the culture medium on Day 6 of culture. $\times 300$. 


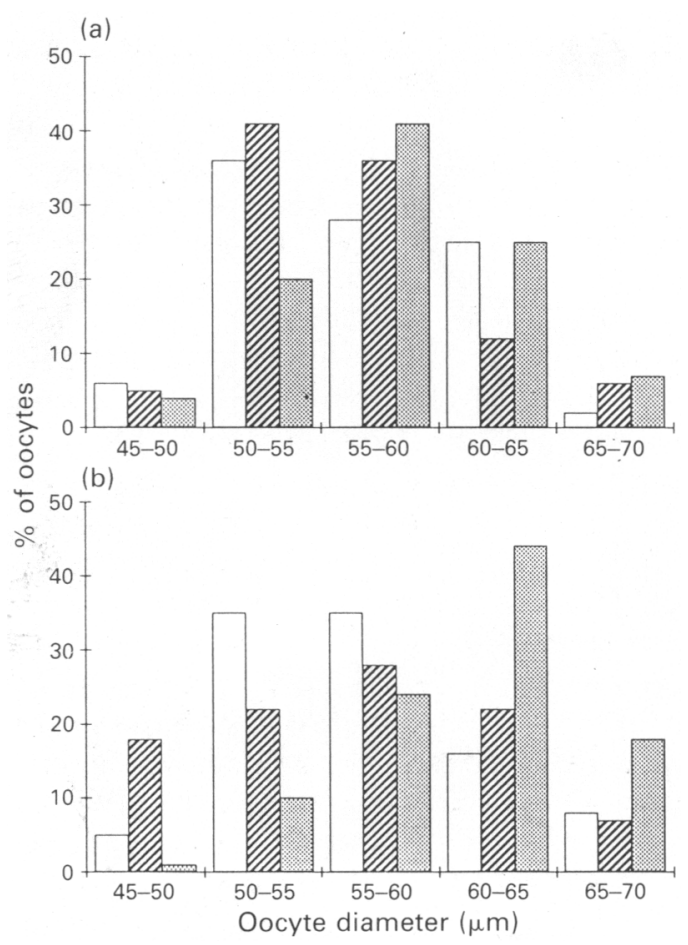

Fig. 3. Distribution of the diameters of mouse oocytes recovered at the germinal vesicle stage after the culture of isolated primary follicles for (a) 9 or (b) 12 days in control medium ( $\square$ ) or medium containing hypoxanthine $(\mathbb{Z})$ or dibutyryl cyclic adenosine monophosphate (dbcAMP) (国) from Day 6 of culture. On Day 9, $n=85,95$ and 89 and on Day 12, $n=81,76$ and 87 for control, hypoxanthine and dbcAMP groups, respectively.

Table 4. Number of granulosa cells present after isolated primary mouse follicles were treated with dibutyryl cyclic adenosine monophosphate (dbcAMP) from Day 6 to 12 of culture

\begin{tabular}{|c|c|c|c|}
\hline Treatment & $\begin{array}{l}\text { No. of granulosa } \\
\text { cells }\left(\times 10^{-3}\right) / 3 \text { gels }\end{array}$ & $\begin{array}{c}\text { No. of } \\
\text { oocytes } / 3 \text { gels }\end{array}$ & $\begin{array}{l}\text { No. of } \\
\text { cells/oocyte }\end{array}$ \\
\hline $\begin{array}{l}\text { Day 0* } \\
\text { Control } \dagger \\
\text { dbcAMP† }\end{array}$ & $\begin{array}{c}- \\
6 \cdot 5 \pm 0.6 \\
32 \cdot 5 \pm 5\end{array}$ & $\begin{array}{l}78 \pm 3 \cdot 7 \\
87 \pm 10\end{array}$ & $\begin{array}{r}164 \pm 38^{\mathrm{a}} \\
838 \pm 93^{\mathrm{b}} \\
3757 \pm 423^{\mathrm{c}}\end{array}$ \\
\hline \multicolumn{4}{|c|}{$\begin{array}{l}\text { *Values were determined from the equivalent number of follicles which } \\
\text { were suspended in } 3 \text { gels on Day } 1 \text { of culture (i.e. } 150 \text { ). Data are from } \\
3 \text { individual experiments with a total of } 9 \text { observations and each was } \\
\text { counted } 4-8 \text { times. } \\
\text { tData are from } 3 \text { experiments with a total of } 4 \text { observations ( } 3 \text { gels } \\
\text { observation), each counted } 4-8 \text { times. } \\
\text { Values with different superscripts are significantly different }(P<0.01 \text { ). }\end{array}$} \\
\hline
\end{tabular}

\section{Discussion}

Culture of 10-day-old postnatal, primary ovarian mouse follicles in a collagen gel matrix in medium containing dbcAMP yielded oocytes which were larger and more competent to resume 
meiosis than those cultured in control or hypoxanthine-containing medium. The present results suggest that the increased oocyte quality is mediated by the effects of dbcAMP on granulosa cell function.

Hypoxanthine has been shown to increase the proportion of oocytes able to resume meiosis at the end of 12-days' culture (Eppig \& Downs, 1987). This effect was attributed mainly to the ability of hypoxanthine to inhibit meiosis during culture, allowing the synchronization of maturation when the meiotic inhibitor was removed at the end of the culture period. It was also observed that fewer oocytes became denuded during the culture period. In the present study, hypoxanthine did not appear to inhibit meiosis during the culture period and had little or no effect on oocyte growth and ability to resume meiosis. The difference between these two studies may reflect differences in the culture systems: in the study of Eppig \& Downs (1987) 50\% of oocytes resumed meiosis spontaneously during culture in control conditions compared with only $7 \%$ in the present study. The addition of dbcAMP to the culture medium did inhibit the resumption of meiosis during culture and improved significantly the ability of oocytes to resume meiosis at the end of the culture period. The ability of dbcAMP to inhibit meiosis during culture would allow for a $7 \%$ increase in the proportion of oocytes able to resume meiosis at the end of the culture period. This is markedly less than the observed increase of $>30 \%$, suggesting that dbcAMP has additional effects on oocyte development. The ability of oocytes to resume meiosis is related to oocyte diameter and occurs in a stepwise manner such that GVBD first occurs at a diameter of $\sim 60 \mu \mathrm{m}$, but extrusion of the first polar body occurs only after the oocyte reaches a diameter of 65-70 $\mu \mathrm{m}$ (Sorenson \& Wassarman, 1976; Eppig \& Schroeder, 1989). Our results clearly show that, in the presence of dbcAMP, oocyte growth improves significantly, with the result that the proportion of oocytes resuming and completing meiosis also increases. These observations suggest that the increase in meiotic competence after the growth of primary follicles in the presence of dbcAMP is primarily due to an increase in oocyte growth and, to a lesser extent, to the inhibition of meiosis during the culture period.

The dbcAMP-induced 4-fold proliferation of the granulosa cells is a likely explanation for improved conditions of oocyte growth. Oocyte growth is dependent upon gap-junction-mediated metabolic coupling with granulosa cells (Brower \& Schultz, 1982; Herlands \& Schultz, 1984); oocytes denuded of their granulosa cells and cultured separately, or in co-culture with them (Eppig, 1979; Bachvarova, et al., 1980) or other cell types (Canipari et al., 1984; Herlands \& Schultz, 1984; Buccione et al., 1987), show little if any growth. Further, our preliminary studies have shown that dbcAMP does not appear to improve the growth of denuded oocytes cultured separately or in co-culture with granulosa cells (J. Carroll, D. G. Whittingham \& M. J. Wood, unpublished observations). Since oocyte growth is a period of high metabolic activity, an increase in the number of granulosa cells surrounding each oocyte may provide a means of supplying the required nutrients. In vivo, early follicular development involves oocyte growth with a concomitant increase in numbers of granulosa cells (Pederson \& Peters, 1968). The observation that granulosa cell proliferation is associated with improved rates of oocyte growth in vitro suggests that oocyte growth and follicular development are interrelated. This may not be the case in vivo, as primary follicles grown in different gonadotrophin environments yield oocytes of similar diameter despite significant differences in the extent of follicular development (J. Carroll, unpublished). Also, when follicular development is disrupted by administration of antisera to gonadotrophins (Eshkol et al., 1970; Purandare et al., 1976) or hypophysectomy (Smith \& Tenney, 1979), there is no apparent effect on oocyte growth. Further development of culture systems which support concomitant follicular and oocyte development may make it possible to determine whether these processes are interdependent.

Factors other than granulosa cell proliferation may also be responsible for improving the rate of oocyte growth observed in the presence of dbcAMP. In many cell systems, hormone-induced increases in cAMP have a role in promoting function and/or differentiation of the target cells as well as proliferation (Boynton \& Whitfield, 1983; Dumont et al., 1989). This is also true for granulosa cells, as dbcAMP is known to increase steroidogenesis (Hsueh et al., 1984) and to produce a 6-fold increase in the secretion of insulin-like growth factor-1 (Hsu \& Hammond, 1987). Our 
preliminary observations (unpublished) show that the culture of primary follicles in the presence of dbcAMP stimulates the production of oestrogen and progesterone. Thus the production of steroids and growth factors may be one means by which granulosa cell function could mediate oocyte growth. Further evidence for a regulatory role of granulosa cells on oocyte development is that protein kinase activity in the oocyte can be affected by granulosa cells (Colonna et al., 1989). Increased concentrations of cAMP could clearly affect this function. The possibility that improved oocyte growth is mediated via dbcAMP-induced changes in granulosa cell function therefore requires further investigation.

The presence of dbcAMP in the culture medium may more closely mimic conditions in vivo. cAMP is the putative second messenger for follicle-stimulating hormone (FSH) and the concentrations of FSH are known to be high in the serum of juvenile mice (Michael et al., 1980). FSH also stimulates granulosa cell mitosis in small follicles in vivo (Ryle, 1969, 1972; Pederson, 1970) and in vitro (Roy \& Greenwald, 1986, 1989); thus the endogenous hormone and dbcAMP appear to have similar effects. The rate of proliferation of granulosa cells in vivo appears similar to that observed in the presence of dbcAMP. Using autoradiography and pulse labelling with tritiated thymidine, Pederson (1970) calculated the doubling time of granulosa cells in follicles similar in size to the ones used in this study to be $\sim 59-84 \mathrm{~h}$. In the present study, the numbers of granulosa cells in control conditions increased from $\sim 160$ /oocyte to 840 /oocyte, which represents a cell doubling every $120 \mathrm{~h}$ compared with, in the presence of dbcAMP, an increase of 160 cells/oocyte to $3760 /$ oocyte or a cell doubling every $64 \mathrm{~h}$. In neither study was it possible to determine whether the increase in numbers of cells was due to a small population of rapidly dividing cells or to the proliferation of the entire granulosa cell population.

The mechanism of the dbcAMP-induced granulosa cell proliferation is not clear. Stimulation of mitosis by dbcAMP may have occurred by a direct effect on the cell nucleus (Boynton \& Whitfield, 1983) and/or by stimulating the production of paracrine/autocrine-acting growth factors (Hsu \& Hammond, 1987) and steroid hormones (Hsueh et al., 1984), which are known to stimulate granulosa cell proliferation. This latter possibility is supported by observations (unpublished) that indicate marked stimulation of oestrogen and progesterone production by primary follicles when cultured in the presence of dbcAMP. A further possibility is that the effects of dbcAMP on granulosa cell proliferation may be mediated by the oocyte. Recent studies have shown that the oocyte is essential for cumulus cell expansion (Buccione et al., 1990; Salustri et al., 1990) demonstrating that the oocyte regulates granulosa cell function and possibly differentiation. It remains to be determined whether the oocyte can regulate follicular development at earlier stages of development. The precise mechanism of granulosa cell proliferation may provide important information on the regulation of follicular development and its relationship to oocyte growth.

The developmental capacity of oocytes grown and matured in vitro has not yet been optimized. In this study, $35 \%$ of oocytes cleaved to the 2-cell stage but none of these developed after transfer to foster mothers. Live young have been produced after the transfer of oocytes grown and matured in vitro (Eppig \& Schroeder, 1989), but the low rate of success ( $5 \%$ of embryos transferred) clearly indicates the need for further delineation of the factors which contribute during oocyte growth to the full developmental capacity of the oocyte.

We thank Professor C. D. Matthews for helpful comments on the manuscript, Dr J. Wang for advice on statistics and Mrs H. Holmes for preparation of the manuscript. J. Carroll was supported by a Reproductive Medicine Postgraduate Scholarship from the Department of Obstetrics and Gynaecology, The University of Adelaide. This study was supported by the Medical Research Council.

\section{References}

Bachvarova, R., Baran, M.M. \& Tejblum, A. (1980) Development of naked growing mouse oocytes in vitro. J. exp. Zool. 211, 159-169.
Boynton, A.L. \& Whitfield, J.F. (1983) The role of cyclic AMP in cell proliferation: A critical assessment of the evidence. Adv. Cyclic Nucleotide Res. 15, 193-294. 
Brower, P.T. \& Schultz, R.M. (1982) Intercellular communication between granulosa cells and mouse oocytes: Existence and possible nutritional role during oocyte growth. Devl Biol. 90, 144-153.

Buccione, R., Cecconi, S., Tatone, C., Mangia, F. \& Calonna, R. (1987) Follicle cell regulation of mammalian oocyte growth. $J$. exp. Zool. 242, $35 \mathrm{I}-354$.

Buccione, R., Vanderhyden, B.C., Caron, P.J. \& Eppig, J.J. (1990) FSH-induced expansion of the mouse cumulus oophorus in vitro is dependent upon a specific factor secreted by the oocyte. Devl Biol. 138, 16-25.

Canipari, R., Palombi, F., Riminucci, M. \& Mangia, F. (1984) Early programming of maturation competence in mouse oogenesis. Devl Biol. 102, 519-524.

Carroll, J. Whittingham, D.G., Wood, M.W., Telfer, E. \& Gosden, R.G. (1990) Extra ovarian production of mature viable mouse oocytes from frozen primary follicles. J. Reprod. Fert. 90, 321-327.

Colonna, R., Cecconi, S., Tatone, C., Mangia, F. \& Buccione, F. (1989) Somatic cell-oocyte interactions in mouse oogenesis: stage specific regulation of mouse oocyte protein phosphorylation by granulosa cells. Devl Biol. 133, 305-308.

Dumont, J.F., Juaniaux, J.C. \& Roger, P.D. (1989) The cyclic AMP mediated stimulation of cell proliferation. Trends in Biochem. Sci. 14, 67-71.

Eppig, J.J. (1979) A comparison between oocyte growth in co-culture with granulosa cells and oocytes with granulosa cell-oocyte junctional contact maintained in vitro. J. exp. Zool. 209, 345-353.

Eppig, J.J. \& Downs, S.M. (1987) The effect of hypoxanthine on mouse oocyte growth and development in vitro: maintenance of meiotic arrest and gonadotropin-induced oocyte maturation. Devl Biol. 119, 313-321.

Eppig, J.J. \& Schroeder, A.C. (1989) Capacity of mouse oocytes from pre-antral follicles to undergo embryogenesis and development to live young after growth, maturation and fertilization in vitro. Biol. Reprod. 42, 268-276.

Eshkol, A., Lunenfeld, B. \& Peters, H. (1970) Ovarian development in infant mice: Dependence on gonadotropic hormones. In Gonadotrophins and Ovarian Development, pp. 249-258. Eds W. R. Butt, A. C. Crook \& M. Ryle. E \& S Livingstone, Edinburgh.

Glenister, P.H., Wood, M.J., Kirby, C. \& Whittingham, D.G. (1987) Incidence of chromosome anomalies in first cleavage mouse embryos obtained from frozenthawed oocytes fertilized in vitro. Gamete Res. 16, 205-2l 6.

Heller, D., Cahill, D. \& Schultz, R.M. (1981) Biochemical studies of mammalian oogenesis: Metabolic cooperativity between granulosa cells and growing oocytes. Devl Biol. 84, 455-464.

Herlands, R.L. \& Schultz, R.M. (1984) Regulation of mouse oocyte growth: probable nutritional role for intercellular communication between follicle cells and oocytes in oocyte growth. J. exp. Zool. 229, $317-325$.
Hsu, C.-J. \& Hammond, J.M. (1987) Gonadotropins and estradiol stimulate immunoreactive insulin like growth factor-l production by porcine granulosa cells in vitro. Endocrinology 120, 198-207.

Hsueh, A.J.W., Adashi, E.Y., Jones, P.B.C. \& Welsh, T.H. (1984) Hormonal regulation of the differentiation of cultured ovarian granulosa cells. Endocr. Rev. 5, 76-126.

Michael, S.D., Kaplan, S.B. \& MacMillan, B.T. (1980) Peripheral plasma concentrations of LH, FSH, prolactin and $\mathrm{GH}$ from birth to puberty in male and female mice. J. Reprod. Fert. 59, 217-222.

Pederson, T. (1970) Cell population kinetics of the ovary of the immature mouse after FSH stimulation. In Gonadotrophins and Ovarian Development, pp. 312324. Eds W. R. Butt, A. C. Crooke \& M. Ryle. E \& S Livingstone, Edinburgh.

Pederson, T. \& Peters, H. (1968) Proposal for a classification of oocytes and follicles in the mouse ovary. $J$. Reprod. Fert. 17, 555-557.

Pincus, G. \& Enzman, E.V. (1935) The comparative behaviour of mammalian eggs in vivo and in vitro. $J$. exp. Med. 62, 665-675.

Purandare, T.V., Munshi, S.R. \& Rao, S.A. (1976) Effect of antisera to gonadotropins on follicular development and fertility of mice. Biol. Reprod. 15, 311-320.

Quinn, P., Barros, C. \& Whittingham, D.G. (1982) Preservation of hamster oocytes to assay the fertilizing capacity of human spermatozoa. J. Reprod. Fert. 66, 161-168.

Roy, S.K. \& Greenwald, G.S. (1986) Effects of FSH and LH on incorporation of $\left[{ }^{3} \mathrm{H}\right]$ thymidine into follicular DNA. J. Reprod. Fert. 78, 201-209.

Roy, S.K. \& Greenwald, G.S. (1989) Hormonal requirements for the growth and differentiation of hamster preantral follicles in long-term culture. J. Reprod. Fert. 87, 103-114.

Ryle, M. (1969) The duration of an FSH effect in vitro. $J$. Reprod. Fert. 19, 349-351.

Ryle, M. (1972) The growth in vitro of mouse ovarian follicles of different sizes in response to purified gonadotrophins. J. Reprod. Fert. 30, 395-403.

Salustri, A., Yanagishita, M. \& Hascall, V.C. (1990) Mouse oocytes regulate hyaluronic acid synthesis and mucification by FSH-stimulated cumulus cells. Devl Biol. 138, 26-32.

Smith, D.M. \& Tenney, D.Y. (1979) Effect of hypophysectomy on mouse oocyte maturation in vitro. $J$. Reprod. Fert. 55, 415 422.

Sorenson, R.A. \& Wassarman, P.M. (1976) Relationship between growth and meiotic maturation of the mouse oocyte. Devl Biol. 50, 531-536.

Torrance, C., Telfer, E. \& Gosden, R.G. (1989) Quantitative study of the development of isolated mouse pre-antral follicles in collagen gel culture. $J$. Reprod. Fert. 87, 367-374.

Whittingham, D.G. (1971) Culture of mouse ova. $J$. Reprod. Fert., Suppl. 14, 7-21.

Received 3 August 1990 